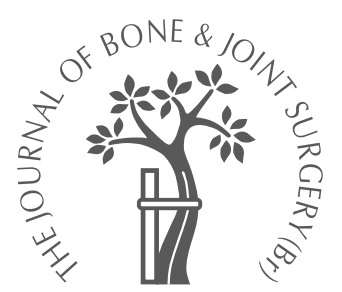

F. Dobson, H. Kerr Graham, R. Baker, M. E. Morris

From The Royal Children's Hospital, Melbourne, and La Trobe University, Victoria, Australia

H. Kerr Graham, MD, FRCSEd, FRACS, Professor of Orthopaedic Surgery R. Baker, PhD, CEng, Gait Analysis Service Manager and Director of Research Hugh Williamson Gait Laboratory, Royal Children's Hospital, Flemington Road, Parkville, Victoria 3052, Australia.

F. Dobson, BAppSc(PT), Research Physiotherapist M. E. Morris, PhD, Professor

School of Physiotherapy, La Trobe University, Victoria 3086, Australia.

Correspondence should be sent to Dr F. Dobson; e-mail: f.dobson@latrobe.edu.au

(C)2005 British Editorial Society of Bone and Joint Surgery doi:10.1302/0301-620X.87B4. $15525 \$ 2.00$

$J$ Bone Joint Surg [Br] 2005;87-B:548-55.

Received 1 April 2004; Accepted 8 July 2004

\section{Multilevel orthopaedic surgery in group IV spastic hemiplegia}

Most children with spastic hemiplegia have high levels of function and independence but fixed deformities and gait abnormalities are common. The classification proposed by Winters et al is widely used to interpret hemiplegic gait patterns and plan intervention. However, this classification is based on sagittal kinematics and fails to consider important abnormalities in the transverse plane. Using three-dimensional gait analysis, we studied the incidence of transverse-plane deformity and gait abnormality in 17 children with group IV hemiplegia according to Winters et al before and after multilevel orthopaedic surgery.

We found that internal rotation of the hip and pelvic retraction were consistent abnormalities of gait in group-IV hemiplegia. A programme of multilevel surgery resulted in predictable improvement in gait and posture, including pelvic retraction. In group IV hemiplegia pelvic retraction appeared in part to be a compensating mechanism to control foot progression in the presence of medial femoral torsion. Correction of this torsion can improve gait symmetry and function.

Spastic hemiplegia is the most common type of cerebral palsy. ${ }^{1}$ It is characterised by unilateral involvement and a high level of activity. Most children with spastic hemiplegia achieve independent walking, but have an asymmetrical gait pattern. They have a slower walking speed, increased energy consumption when walking and spend less time on their feet than their peers. ${ }^{2,3}$ Psychosocial issues include lower self-esteem, self-consciousness about the cosmetic aspects of their gait and parental anxiety. ${ }^{4}$

When the child with spastic hemiplegia starts to walk, the characteristic position of the upper limb combined with toe-walking, caused by spastic equinus, is the most common presentation. Methods of treatment in the younger child include intramuscular injections of botulinum toxin $\mathrm{A}$ and the provision of an ankle-foot orthosis. ${ }^{5}$ The older child may benefit from lengthening of tendo Achillis for a fixed equinus deformity. ${ }^{6}$ Equinovarus and equinovalgus deformities are also common and may require tendon transfers and foot stabilisation, respectively. ${ }^{7,8}$ The role of multilevel surgery is less well accepted.

The classification of hemiplegic gait as described by Winters, Gage and Hicks ${ }^{9}$ is widely used. There are four groups. Group I is characterised by a drop foot during the swing phase of gait and group II by equinus in both stance and swing phases because of a fixed equinus contracture. Group III includes involvement at the knee, with a flexed, stiff-knee gait and group IV involves the hip with increased flexion and reduced movement at both hip and knee and equinus at the ankle. The main limitation of this classification is that it is based on data relevant to the sagittal plane only, whereas significant gait abnormalities in the coronal and transverse planes have also been described. ${ }^{10-12}$ Typical abnormalities in the transverse plane include internal foot progression, medial rotation of the hip, and pelvic retraction. , $^{6,10,11}$

In the past, pelvic retraction and asymmetry in hemiplegia were considered to be a primary neurological deficit related to the lesion of the central nervous system. ${ }^{13,14}$ The neurodevelopmental approach to treatment emphasises the importance of correcting pelvic asymmetry in hemiplegic gait. ${ }^{13}$ However, pelvic retraction may be the result of biomechanical problems associated with weakness and deformity on the hemiplegic side rather than a primary neurological deficit. It may also be a tertiary or a voluntary coping response to maintain a more neutral foot progression angle, in the presence of increased medial femoral torsion (Fig. 1). ${ }^{10,15,16}$ If pelvic asymmetry in hemiplegia is a voluntary compensation for medial femoral torsion, then correction of the femoral deformity should correct the pelvic asymmetry. 
a
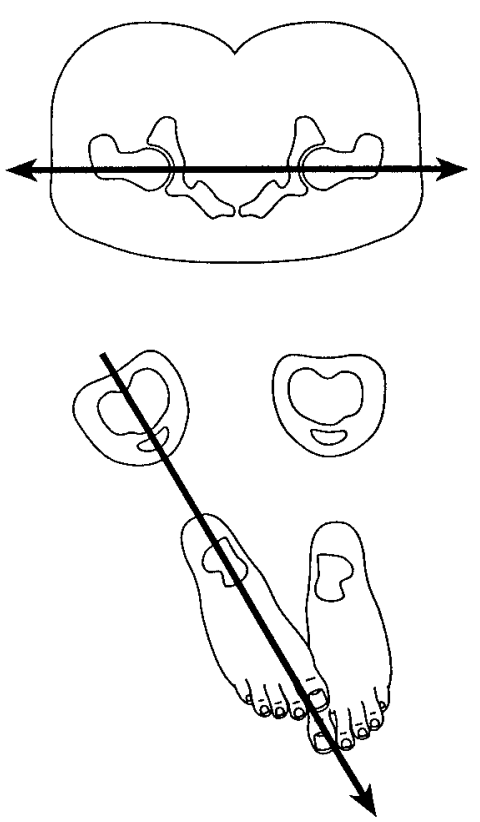

b
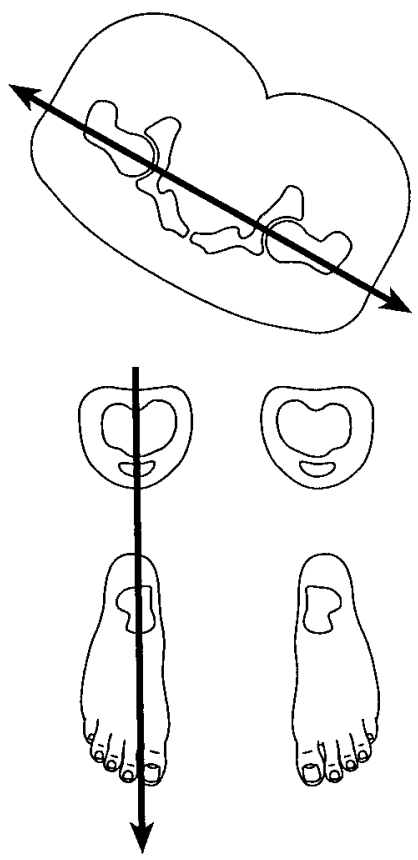

c
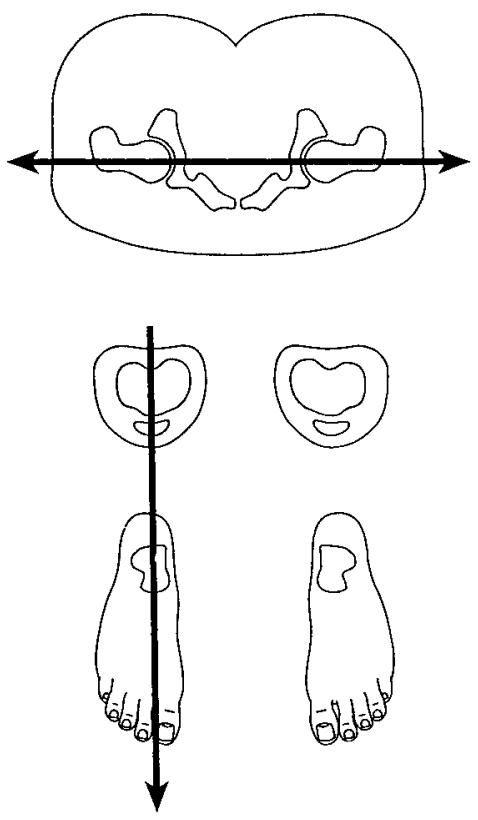
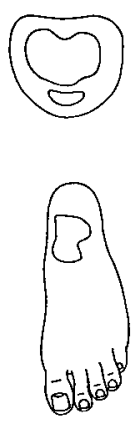

Fig. 1

Diagram of internal rotation gait in spastic hemiplegia. Figure $1 \mathrm{a}-$ When standing with the pelvis parallel to a line at $90^{\circ}$ to the line of progression the internal rotation at the femur is evident with a corresponding internal foot progression angle. Figure $1 \mathrm{~b}-$ However, during walking the foot progression angle is controlled by voluntary pelvic retraction on the affected side. Figure 1c The lower limb is seen to be pointing almost directly forwards. After correction of medial femoral torsion the pelvis is able to assume a more neutral position since it no longer needs to compensate to keep the lower limb in the line of progression.

Our aim was to examine the incidence of deformities and gait abnormalities in the transverse plane in a cohort of children with group IV spastic hemiplegia according to the definition of Winters et al. ${ }^{9}$ We also wished to study the effects of multilevel surgery on fixed deformities, gait abnormalities and pelvic asymmetry in these children.

\section{Patients and Methods}

In this prospective cohort study, we included all patients who had been seen in our motion analysis laboratory between 1995 and 2001 with a diagnosis of group IV spastic hemiplegia which had been managed by single-event, multilevel surgery, and who had a minimum clinical and gait laboratory follow-up of two years. Patients with previous surgery for equinus deformity were included but not those with previous bony surgery.

Seventeen patients (14 males and three females) fulfilled the study criteria. The mean age at surgery was 12.1 years (7.1 to 17.1). The mean number of surgical procedures was 4.2 (2 to 7). The surgical procedures for each subject, the age at surgery and the duration of follow-up are given in Table I. Nine additional patients with group IV hemiplegia were seen during the period of study, but excluded from the analysis because of inadequate follow-up or staged surgical procedures.

A rigid definition was used for hemiplegia, ${ }^{17}$ which included unilateral neurological involvement with the characteristic position of the upper-limb and lower-limb involvement on static examination and during gait. On the contralateral side neurological examination was normal with a downgoing plantar response, no clonus or spasticity and preservation of selective motor control.

Each patient underwent a quantitative biomechanical assessment. This included a comprehensive history, a standardised clinical examination, radiography of the pelvis and feet, three-dimensional analysis of movement and examination under anaesthesia, immediately before surgery.

The passive range of movement of the hips, knees and ankles was measured using a previously described protocol. $^{18}$ Selective motor control and muscle strength were recorded according to previously described techniques. ${ }^{19,20}$ Measurements of femoral torsion (femoral neck anteversion, FNA) were made as described by Ruwe et $\mathrm{a}^{21}$ and foot position by thigh foot angle, as described by Staheli. ${ }^{22,23}$ All angles were measured using a standard goniometer. ${ }^{24}$ The migration percentage and acetabular index were measured from standardised anteroposterior views of the pelvis. ${ }^{25}$

Quantitative three-dimensional analysis of movement was carried out using a $50 \mathrm{~Hz}$ six-camera Vicon 370 system (Oxford Metrics, Oxford, UK) and two forceplates (Advanced Mechanical Technology Inc, Newton, Massachusetts). Reflective markers were applied to the bony landmarks of the lower limb using a standardised procedure. ${ }^{26}$ 
Table I. Details of the patients, side of hemiplegia, age at surgery, follow-up and surgical treatment in the 17 children with group-IV spastic hemiplegia

\begin{tabular}{|c|c|c|c|c|c|c|c|c|c|c|c|c|c|}
\hline \multirow[b]{2}{*}{ Case } & \multirow{2}{*}{$\begin{array}{l}\text { Hemiplegic } \\
\text { side }\end{array}$} & \multirow{2}{*}{$\begin{array}{l}\text { Surgery } \\
\text { (yrs) }\end{array}$} & \multirow{2}{*}{$\begin{array}{l}\text { Age at latest } \\
\text { follow-up (yrs) }\end{array}$} & \multirow{2}{*}{$\begin{array}{l}\text { Duration of } \\
\text { follow-up } \\
\text { (yrs) }\end{array}$} & \multicolumn{9}{|c|}{ Surgery ${ }^{*}$} \\
\hline & & & & & FDO & VDRO & Psoas & MHS & LHS & RFT & Add & Calf & TPR \\
\hline 1 & $\mathrm{R}$ & 9.9 & 13.1 & 3.2 & & 1 & & 1 & & 1 & & $\mathrm{GR}$ & \\
\hline 2 & $\mathrm{~L}$ & 13.0 & 16.4 & 3.4 & 1 & & & 1 & & 1 & & GR & \\
\hline 3 & $\mathrm{~L}$ & 8.2 & 10.2 & 2.0 & & 1 & & 1 & & 1 & & & \\
\hline 4 & $\mathrm{~L}$ & 10.6 & 12.8 & 2.8 & 1 & & & & & & $P$ & TAL & \\
\hline 5 & $\mathrm{~L}$ & 15.8 & 18.0 & 2.3 & & 1 & & 1 & & 1 & & GR & \\
\hline 6 & $\mathrm{R}$ & 11.0 & 14.9 & 3.9 & 1 & & & 1 & & 1 & & GR & \\
\hline 7 & $\mathrm{R}$ & 14.8 & 16.8 & 2.8 & & 1 & & 1 & 1 & 1 & & TAL & \\
\hline 8 & $\mathrm{~L}$ & 15.5 & 17.8 & 2.3 & & 1 & 1 & 1 & & 1 & 0 & TAL & \\
\hline 9 & $\mathrm{R}$ & 17.1 & 20.0 & 2.9 & 1 & & & 1 & & & & TAL & 1 \\
\hline 10 & $\mathrm{R}$ & 12.6 & 14.7 & 2.1 & 1 & & & 1 & & 1 & $P$ & & \\
\hline 11 & $\mathrm{~L}$ & 13.6 & 15.9 & 2.3 & 1 & & & 1 & & & $P$ & TAL & \\
\hline 12 & $\mathrm{~L}$ & 9.3 & 14.8 & 5.5 & 1 & & & & & & & TAL & \\
\hline 13 & $\mathrm{~L}$ & 9.4 & 12.4 & 3.0 & 1 & & & & & 1 & $P$ & & 1 \\
\hline 14 & $\mathrm{R}$ & 7.1 & 9.7 & 2.6 & 1 & & & & & & & TAL & \\
\hline 15 & $\mathrm{R}$ & 15.3 & 18.5 & 3.2 & & 1 & & 1 & 1 & 1 & $P$ & & \\
\hline 16 & $\mathrm{R}$ & 13.6 & 15.6 & 2.0 & 1 & & & 1 & & 1 & $P$ & GR & \\
\hline 17 & $\mathrm{R}$ & 9.4 & 12.9 & 3.5 & 1 & & 1 & 1 & & 1 & $P$ & GR & 1 \\
\hline Total & & & & & 11 & 6 & 2 & 13 & 2 & 12 & 8 & 13 & 3 \\
\hline Mean & & 12.9 & 15.0 & 2.9 & & & & & & & & & \\
\hline SD & & 4.4 & 2.9 & 0.9 & & & & & & & & & \\
\hline
\end{tabular}

* FDO, femoral derotation osteotomy; VDRO, varus derotation osteotomy; Psoas, psoas lengthening over the pelvic brim; MHS, medial hamstrong lengthening; LHS, lateral hamstring lengthening; RFT, rectus femoris transfer; Add, adductor longus lengthening; $P$, percutaneous lengthening; $O$, open lengthening; Calf, calf lengthening procedure; GR, gastrocnemius recession, TAL, tendo Achillis lengthening; TPR, tibialis posterior recession

Euler angles and inverse dynamics were used to calculate kinematics and kinetics using the Vicon Clinical Manager (Oxford Metrics). The primary outcome measures were selected temporospatial data and three-dimensional kinematics. Patients were asked to walk barefoot in their usual manner along a 10-metre walkway. In order to obtain 'typical' walking data from each patient, a representative trial was chosen for analysis from a number of trials with a minimum of three clean forceplate contacts per side and when possible five per side. Two experienced physiotherapists were responsible for all collection of data. The gait model used referenced pelvic position and foot progression in relation to the line of progression in the motion analysis laboratory. Hip, knee and ankle kinematic data were reported with reference to the proximal limb segment.

Operative intervention. Operative procedures were selected for each patient based on their symptoms, functional goals and quantitative biomechanical assessment. Equinus deformity was corrected either by lengthening of the gastrocnemius fascia, as described by $\operatorname{Strayer}^{27}$ or by slide lengthening of tendo Achillis as described by White ${ }^{28}$ and modified by Graham and Fixsen. ${ }^{29}$ The choice was based on the Silfverskiold test, performed under anaesthesia. ${ }^{16}$ Hindfoot varus and forefoot adductus were treated by recession of tibialis posterior as described by Ruda and Frost. $^{30}$

Flexed knee gait was treated by lengthening of the medial hamstrings with the addition of lengthening of the lateral hamstrings if the flexion contracture of the knee was more than $10^{\circ}$. Transfer of rectus femoris to semitendinosis was performed for symptomatic stiff-knee gait if the kinematics in the swing phase showed a reduction and delay in peak knee flexion and the prone rectus femoris test was positive. $^{31}$

Lengthening of the psoas over the brim of the pelvis, as described by Sutherland et $\mathrm{al}^{32}$ was performed for excessive hip flexion during gait and if Thomas's test, as described in Keenan et $a 1,{ }^{18}$ indicated a flexion contracture of the hip of more than $20^{\circ}$. Percutaneous or open lengthening of adductor longus was performed if hip abduction in flexion was reduced by more than $20^{\circ}$ on the affected side, compared with the unaffected side and if the hip radiograph showed hip dysplasia or subluxation.

An external rotation osteotomy of the proximal femur at the intertrochanteric level ${ }^{33}$ was performed if internal rotation of the hip was greater than $20^{\circ}$ throughout the stance phase and if anteversion of the femoral neck exceeded $35^{\circ}$ or was more than $20^{\circ}$ greater on the hemiplegic side compared with the unaffected side. Between $10^{\circ}$ and $20^{\circ}$ of varus was added to the osteotomy if the pelvic radiograph showed a migration percentage of more than $20 \%$.

An infusion of bupivacaine and fentanyl by epidural catheter was used for post-operative analgesia. Femoral osteotomies were internally fixed and immobilisation in a cast limited to a below-knee cast for surgical correction of equinus/varus. A removable knee immobiliser was used for six weeks in all patients with either lengthening of the hamstrings or combined lengthening of the hamstrings with transfer of the rectus femoris to the semitendinosus. Patients were discharged from hospital when epidural analgesia was changed to oral analgesia, at a mean of four days (3 to 6). Full weight-bearing was encouraged from two 
Table II. Mean (SD) clinical measurements for the hemiplegic and unaffected sides pre- and post-operatively

\begin{tabular}{|c|c|c|c|c|}
\hline \multirow[b]{2}{*}{ Clinical measurements $\left({ }^{\circ}\right)^{*}$} & \multicolumn{2}{|c|}{ Hemiplegic side } & \multicolumn{2}{|l|}{ Unaffected side } \\
\hline & Pre-operative & Post-operative & Pre-operative & Post-operative \\
\hline \multicolumn{5}{|l|}{ Sagittal plane } \\
\hline Thomas's test & $-7.9(6.2)$ & $-4.7(3.7)^{\dagger}$ & $-0.6(1.7)$ & $-1.8(3.3)$ \\
\hline Popliteal angle & $60.9(13.0)$ & $57.1(11.0)$ & $53.8(11.4)$ & $52.9(10.3)$ \\
\hline True popliteal angle & $49.7(12.1)$ & $43.2(12.5)^{\dagger}$ & $40.6(9.1)$ & $38.8(9.3)$ \\
\hline Knee extension & $-5.3(6.7)$ & $-2.9(6.8)$ & $1.2(2.8)$ & $0.8(1.9)$ \\
\hline Ankle DF (knee at $90^{\circ}$ ) & $2.1(14.1)$ & $11.8(9.3)^{\dagger}$ & $19.1(1.8)$ & $15.6(10.1)^{\dagger}$ \\
\hline Ankle DF (knee at $0^{\circ}$ ) & $-7.4(11.7)$ & $0.1(6.8)^{\dagger}$ & $5.3(8.6)$ & $1.8(7.5)^{\dagger}$ \\
\hline Dynamic ankle DF & $-20.3(11.5)$ & $-5.9(5.9)^{\ddagger}$ & $-6.8(9.9)$ & $-5.0(6.1)$ \\
\hline \multicolumn{5}{|l|}{ Transverse plane } \\
\hline Hip internal rotation & $70.0(9.2)$ & $39.7(12.8)^{\ddagger}$ & $52.9(12.8)$ & $50.6(11.7)$ \\
\hline Hip external rotation & $6.5(15.6)$ & $25.3(12.3)^{\dagger}$ & $27.7(13.4)$ & $24.1(11.9)$ \\
\hline FNA & $44.7(10.5)$ & $25.6(11.7)^{\ddagger}$ & $32.4(2.6)$ & $32.4(8.9)$ \\
\hline FTA & $3.2(10.5)$ & $7.7(11.2)^{\dagger}$ & $4.4(8.2)$ & $6.2(7.6)$ \\
\hline
\end{tabular}

weeks after surgery. The cast was removed after six weeks and replaced by an ankle-foot orthosis. A communitybased rehabilitation programme was arranged for each patient comprising of hourly sessions of physiotherapy and hydrotherapy for a total duration 20 to 30 hours. Followup was by a visit to the motion analysis laboratory for examination and video recording every three months for the first year after surgery and for a three-dimensional gait analysis one year after surgery and yearly clinical examination and video recording of gait thereafter.

Statistical analysis. For the clinical examination data, group means and SDs were calculated for the affected and nonaffected side both pre- and post-operatively and for kinematic data for pelvic rotation during the entire gait cycle. For the hip rotations and foot progressions, these measurements were taken from the stance phase only. The data were then checked for normality. Pre- and post-operative comparisons were made using paired, two-tailed $t$-tests.

For the pelvis, hip and foot the mean difference, in degrees, between the affected and unaffected kinematic waveforms was then calculated both pre- and post-operatively to determine an 'asymmetry score'. For the pelvis only, this score was then categorised into one of five groups on a 'pelvic asymmetry index' as follows: 1 ) normal, $0^{\circ}$ to $5^{\circ}$;2) mild asymmetry, $6^{\circ}$ to $15^{\circ}$; 3 ) moderate asymmetry, $16^{\circ}$ to $25^{\circ}$; 4) severe asymmetry, $26^{\circ}$ to $40^{\circ}$; and 5) extreme asymmetry, $>40^{\circ}$.

\section{Results}

Complications. One patient had poor control of post-operative pain because of a leaking epidural catheter. This was replaced by a morphine infusion and patient-controlled analgesia. Maximum blood loss was $9 \%$ of the estimated blood volume and no patient required a blood transfusion. There were three superficial wound infections, one in an anterior knee incision for rectus femoris transfer and two in the popliteal fossa, after surgery on the hamstrings. ${ }^{9}$ These resolved after dressings and the administration of oral anti-

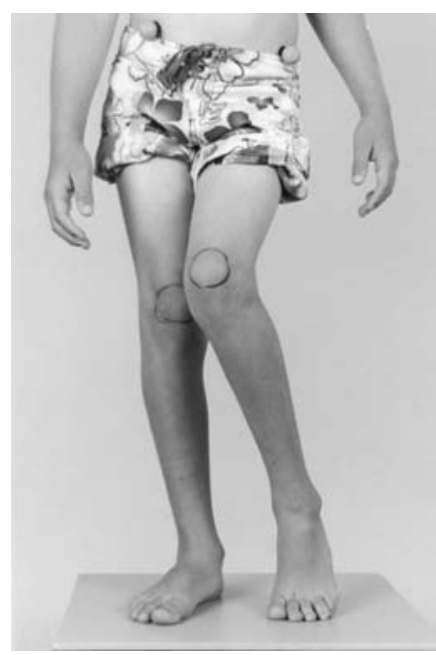

Fig. $2 a$

Fig. 2c

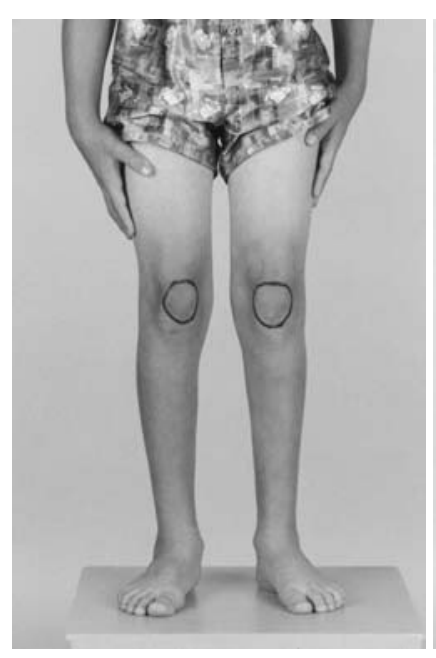

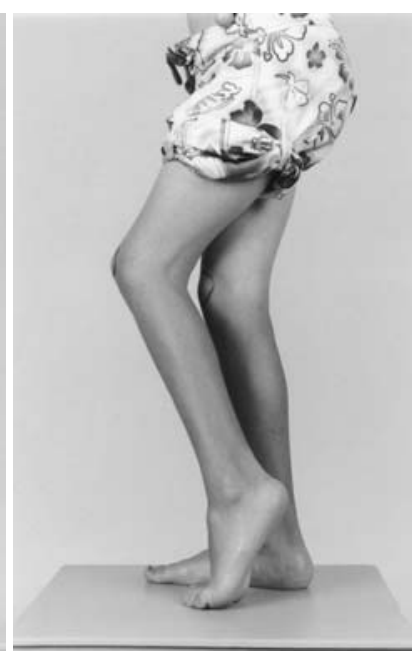

Fig. $2 b$

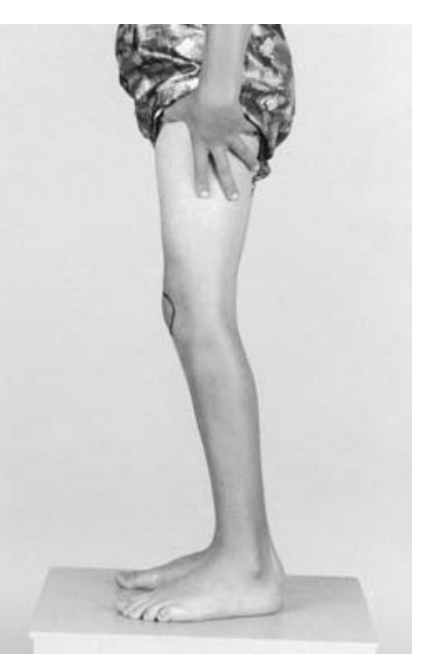

Fig. 2d

Typical standing postures pre-operatively viewed from a) the front and b) the side and post-operatively viewed from c) the front and d) the side. 
Table III. Mean (SD) transverse plane kinematics and asymmetry scores for the affected side and unaffected side pre- and post-operatively. At the pelvis negative values indicate pelvic retraction. At the hip, positive values are internal rotation and negative values are external rotation. At the foot positive values are internal rotation, negative values are external rotation

\begin{tabular}{|c|c|c|c|c|c|c|}
\hline \multirow[b]{2}{*}{ Kinematic rotations $\left({ }^{\circ}\right)$} & \multicolumn{2}{|c|}{ Hemiplegic side } & \multicolumn{2}{|l|}{ Unaffected side } & \multicolumn{2}{|c|}{ Asymmetry scores } \\
\hline & Pre-operative & Post-operative & Pre-operative & Post-operative & Pre-operative & Post-operative \\
\hline Pelvis & $-13.7(6.2)$ & $-4.9(6.2)^{*}$ & $13.6(6.6)$ & $5.3(6.8)^{*}$ & $27.3(12.6)$ & $10.2(12.8)^{*}$ \\
\hline Hip & $23.3(6.9)$ & $-1.5(10.7)^{*}$ & $-6.0(9.4)$ & $2.4(10.4)^{\dagger}$ & $29.3(11.2)$ & $14.0(8.9)^{*}$ \\
\hline Foot & $10.9(16.4)$ & $-13.4(14.5)^{*}$ & $1.3(10.4)$ & $-3.9(14.0)$ & $9.6(10.4)$ & $9.5(13.0)$ \\
\hline
\end{tabular}

$* \mathrm{p}<0.001$

$+p<0.05$
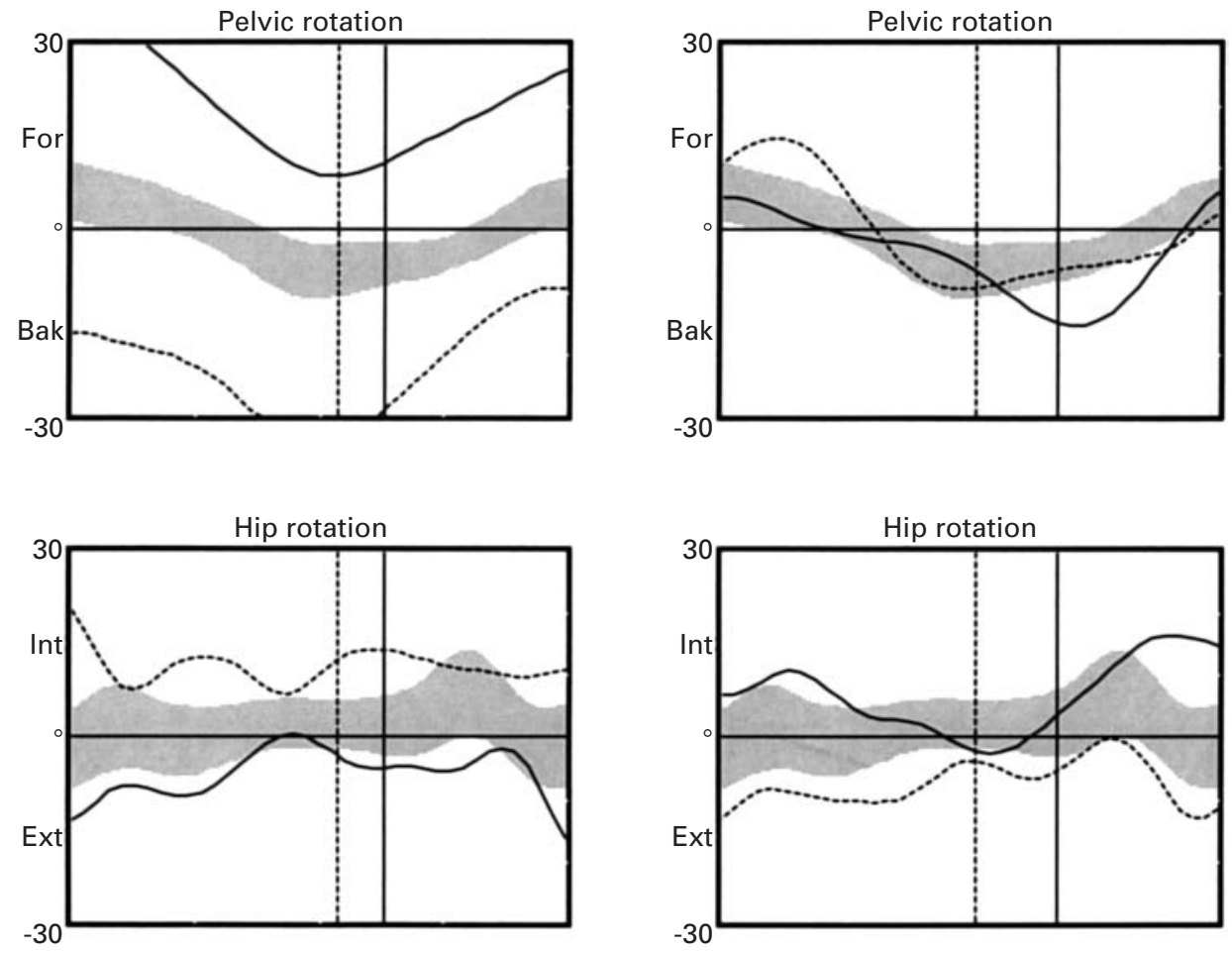

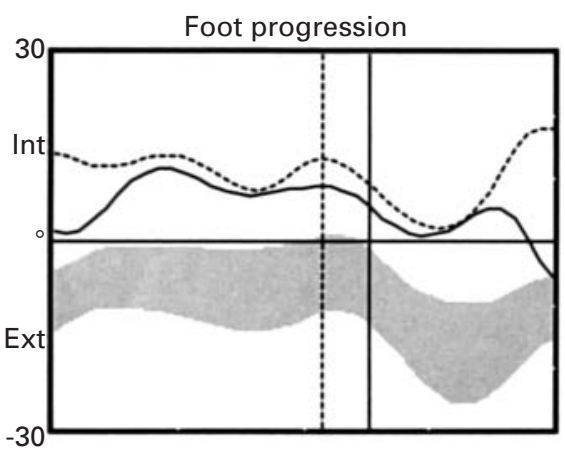

Fig. 3a

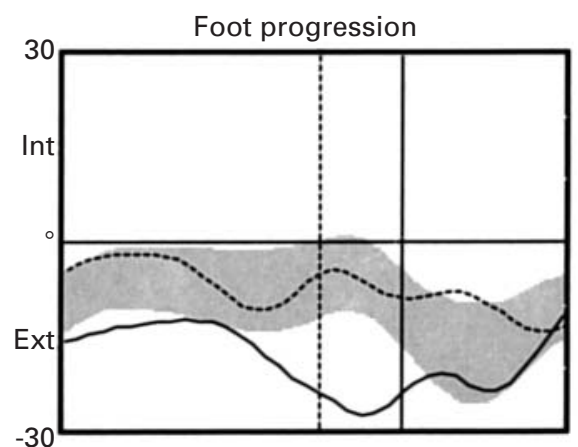

Fig. 3b

Transverse plane kinematics a) pre-operatively and b) post-operatively giving representative data for one gait cycle with toe-off marked by vertical lines. The dashed line is the affected and the solid line the unaffected sides. The normal band (mean \pm 1 SD from the Hugh Williamson Gait Analysis Service normal data) is in grey. Pre-operatively, pelvic asymmetry is marked and is within the extreme range on the pelvic asymmetry index, the affected hip is internally rotated and the affected foot progression is internal. Post-operatively, pelvic asymmentry has improved by three categories on the pelvic asymmetry index and is within the normal range of symmetry, the affected hip is slightly external and the affected foot progression is within normal limits. 


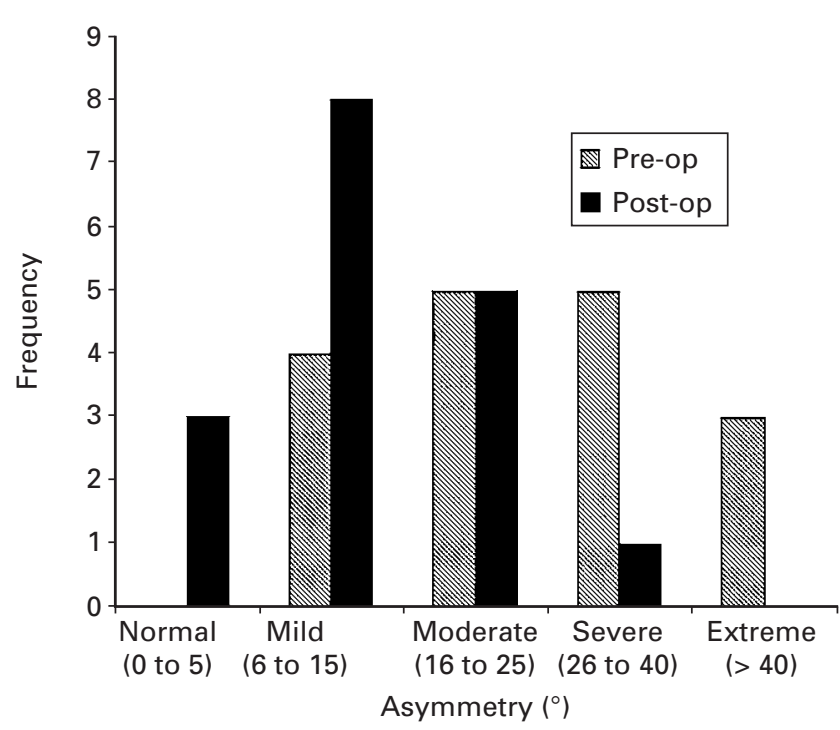

Fig. 4

The pelvic asymmetry index pre- and post-operatively.

biotics. All osteotomies united six weeks after surgery. There were no cases of infection or nonunion. There was insufficient rotational correction in one patient which was not recognised until nine months after surgery.

Clinical and radiological findings. The results for the clinical measurements are summarised in Table II. On the affected side, there was significant correction of hip flexion and hamstring and equinus contractures. External rotation osteotomy of the femur resulted in a decrease in FNA, a decrease in the range of internal rotation of the hip, and an increase in the range of external rotation. The improve- ments in knee extension and thigh-foot-angle were not statistically significant. The typical standing postures viewed from the front and side pre- and post-operatively are shown in Figure 2.

The migration percentage of the five patients who had a varus component to their femoral osteotomy decreased by $16.6 \%$ (SD 8.3) as a result of a decrease in the femoral neckshaft angle of $15.7^{\circ}$ (SD 4.7).

Temporospatial, kinematic and asymmetry data. The mean pre-operative gait speed was $1.09 \mathrm{~m} / \mathrm{s}$ (SD 0.15) and postoperatively this increased to a mean of $1.14 \mathrm{~m} / \mathrm{s}$ (SD 0.18), which was not significant.

The mean values and standard deviations for the transverse plane kinematic data are given in Table III and the average trial is represented in Figure 3. The asymmetry scores both pre- and post-operatively are also outlined in Table III and represented as an asymmetry severity index in Figure 4.

There were clinically and statistically significant improvements in the mean transverse plane kinematic rotations for the pelvis, hip and foot progression $(\mathrm{p}<0.001)$ with all traces moving towards the normal range.

The mean values and standard deviations for selected sagittal plane kinematic data are given in Table IV. For the affected side, there were clinically and statistically significant improvements for all ankle parameters studied and at the knee for extension in stance and peak flexion in swing.

Gait symmetry improved, as seen by a significant decrease in pelvic retraction, internal hip rotation and internal foot progression, on the affected side. Thirteen of the 17 subjects improved by at least one grade in the pelvic asymmetry index, with three subjects adopting pelvic rotations within the normal range in the transverse plane.

Table IV. Selected mean (SD) kinematics $\left({ }^{\circ}\right)$ on the sagittal plane for the affected and unaffected sides pre- and post-operatively

\begin{tabular}{|c|c|c|c|c|}
\hline \multirow[b]{2}{*}{ Clinical measurements $\left(^{\circ}\right)$} & \multicolumn{2}{|c|}{ Hemiplegic side } & \multicolumn{2}{|l|}{ Unaffected side } \\
\hline & Pre-operative & Post-operative & Pre-operative & Post-operative \\
\hline \multicolumn{5}{|l|}{ Hip kinematics } \\
\hline Maximum flexion & $46.0(6.8)$ & $42.3(7.0)$ & $51.8(9.3)$ & $48.5(6.6)$ \\
\hline Minimum flexion & $4.6(8.7)$ & $4.9(8.4)$ & $0.2(6.8)^{*}$ & $-5.4(6.8)^{*}$ \\
\hline Range of motion & $41.4(8.9)$ & $37.4(11.5)$ & $51.6(12.5)$ & $53.9(7.2)$ \\
\hline \multicolumn{5}{|l|}{ Knee kinematics } \\
\hline Value at initial contact & $24.9(9.5)$ & $19.1(7.0)^{\dagger}$ & $18.1(7.8)$ & $17.5(9.9)$ \\
\hline Peak extension in stance & $8.0(16.2)$ & $11.3(6.4)$ & $10.9(9.6)$ & $7.6(8.1)^{\dagger}$ \\
\hline Peak flexion in swing & $49.3(9.2)$ & $55.2(8.1)^{*}$ & $63.9(9.8)$ & $63.8(5.9)$ \\
\hline Timing of peak flexion in swing, as $\% \mathrm{GC}^{\ddagger}$ & $76.1(4.4)$ & $74.7(3.9)$ & $75.2(3.4)$ & $75.8(3.3)$ \\
\hline Range of motion & $41.3(16.3)$ & $44.0(11.3)$ & $53.0(15.9)$ & $56.3(7.4)$ \\
\hline \multicolumn{5}{|l|}{ Ankle kinematics ${ }^{\S}$} \\
\hline Value at initial contact & $-16.9(11.2)$ & $-6.8(7.9)^{*}$ & $-2.4(5.6)$ & $-0.6(7.9)$ \\
\hline Maximum dorsiflexion in stance & $-0.6(12.5)$ & $11.1(7.4)^{\dagger}$ & $9.8(11.1)$ & $13.9(6.8)$ \\
\hline Minimum dorsiflexion in stance & $-24.4(12.9)$ & $-11.8(10.6)^{\dagger}$ & $-12.4(11.2)$ & $-11.8(8.6)$ \\
\hline Mean dorsiflexion in stance & $-7.4(12.2)$ & $3.47(6.6)^{\dagger}$ & $1.3(10.0)$ & $4.7(6.1)$ \\
\hline Maximum dorsiflexion in swing & $-10.9(11.4)$ & $-1.63(7.2)^{\dagger}$ & $-1.25(11.4)$ & $4.6(4.4)$ \\
\hline
\end{tabular}

\footnotetext{
$* p<0.01$

$+p<0.05$

$\ddagger \% \mathrm{GC}$, percentage of gait cycle

$\S$ negative denotes range in plantar flexion
} 


\section{Discussion}

The correction of fixed deformities to improve gait and function are important priorities for children with spastic hemiplegia and their parents. Despite many reports describing the correction of equinus, equinovarus and equinovalgus, there have been few studies reporting the outcome of multilevel surgery in these patients. ${ }^{15,34,35}$

Our data were collected prospectively, in a standardised manner. A rigid definition of spastic hemiplegia and group IV hemiplegic gait were used. However, patients varied in the degree of neurological involvement and abnormality of gait. In addition, multilevel surgery made the interpretation of the outcome of individual procedures much more difficult.

We rigorously applied the kinematic criteria for the diagnosis of group IV hemiplegia in our patients, but not all the deformities and gait abnormalities in the sagittal plane were of sufficient magnitude to require surgical correction in every patient (Table II). However, all patients had evidence of increased FNA and excessive internal rotation of the hip during gait. Five had radiological evidence of subluxation of the hip. We suggest that medial femoral torsion, internal hip rotation and pelvic asymmetry are defining characteristics of group IV hemiplegia and our corrective gait surgery was based on external rotation osteotomy of the femur in all patients. This resulted in the correction of medial femoral torsion, improvement in hip rotation in all 17 patients and improvement in pelvic asymmetry in 16 of 17 patients.

Soft-tissue surgery for muscles acting principally in the sagittal plane was successful in the correction of fixed deformity and gait abnormalities. Clinically and statistically significant improvement in dynamic function of the ankle was found in all five kinematic parameters studied (Table IV). Improvement in dynamic function of the knee was also recorded in the stance and swing phase as a result of lengthening of the hamstrings and transfer of rectus femoris to semitendinosus, respectively. Knee extension at initial contact increased by $5.8^{\circ}$, and peak knee flexion by $5.9^{\circ}$ and occurred earlier in the gait cycle. Both these factors improved foot clearance. There was significant improvement in peak hip and knee extension on the unaffected side, secondary to the improvement in alignment and gait on the affected side.

Severe pelvic retraction results in a crab-like gait, with the pelvis rotated backwards away from the line of progression. There is no evidence that physiotherapy can correct pelvic retraction, although correction is often thought to be important and has been attempted using neurodevelopmental techniques. ${ }^{14,36,37}$

The results show that pelvic asymmetry in children with group IV spastic hemiplegia can be significantly improved by multilevel surgery which supports the hypothesis that pelvic retraction is not solely a primary neurological deficit. It may be secondary to weakness and deformity on the hemiplegic side or a tertiary coping mechanism to maintain a more neutral foot progression angle in the presence of increased medial femoral torsion or a combination of both. It is not possible to determine the relative importance of these factors without staging surgery to investigate the individual effect of each procedure.

Sixteen of the 17 patients showed an improvement towards a more neutral pelvic position after multilevel surgery. In 13 the asymmetry index improved by at least one grade but remained unchanged in three. One patient did not show any improvement in pelvic asymmetry post-operatively and little improvement in medial femoral torsion.

Self-selected walking speed has been shown to be a simple and relevant functional outcome measure after multilevel surgery in spastic diplegia. ${ }^{38}$ Most of our patients had an increase in walking speed and although the increase for the whole cohort was not significant, surgical intervention was not detrimental to this functional outcome.

We wish to acknowledge the help of Mary Sheedy in the preparation and editing of this manuscript, Jill Rodda, Roslyn Boyd and the staff of the Hugh Williamson Gait Analysis Laboratory who provided the data on gait, Gary Nattrass for allowing us to include patients under his care and physiotherapist Adrienne Harvey who supervised the rehabilitation programme.

Research towards this project was carried out whilst the first author was supported by a La Trobe University Postgraduate Research Scholarship. H. Kerr Graham, R. Baker and M. E. Morris are supported in part by a National Health and Medical Research Council Clinical Centre of Research Excellence (CCRE) grant.

No benefits in any form have been received or will be received from a commercial party related directly or indirectly to the subject of this article.

\section{References}

1. Stanley F, Blair E, Alberman E. Cerebral palsies: epidemiology and causal pathways. Clinics in developmental medicine. No. 151. London: MacKeith Press, 2000:1439.

2. Duffy CM, Hill AE, Cosgrove AP, Corry IS, Graham HK. Energy consumption in children with spina bifida and cerebral palsy: a comparative study. Dev Med Child Neurol 1996;38:238-43

3. Pirpiris M, Wilkinson AJ, Rodda JM, et al. Walking speed in children and young adults with neuromuscular disease: comparison between two assessment methods. J Pediatr Orthop 2003;23:302-7.

4. Wake M, Salmon L, Reddihough D. Health status of Australian children with mild to severe cerebral palsy: cross-sectional survey using the Child Health Questionnaire. Dev Med Child Neurol 2003;45:194-9

5. Graham HK. Botulinum toxin type A management of spasticity in the context of orthopaedic surgery for children with spastic cerebral palsy. Eur J Neurol 2001;8(Suppl 5):30-9.

6. Graham HK, Selber P. Musculoskeletal aspects of cerebral palsy. J Bone Joint Surg [Br] 2003;85-B:157-66

7. Mosca VS. Calcaneal lengthening for valgus deformity of the hindfoot: results in children who had severe, symptomatic flatfoot and skewfoot. J Bone Joint Surg [Am] 1995;77-A:500-12.

8. Green NE, Griffin PP, Shiavi R. Split posterior tibial-tendon transfer in spastic cerebral palsy. J Bone Joint Surg [Am]1983;65-A:748-54.

9. Winters TF Jr, Gage J, Hicks R. Gait patterns in spastic hemiplegia in children and young adults. J Bone Joint Surg [Am] 1987;69-A:437-41.

10. Novacheck TF. Management options for gait abnormalities. In: Neville B, Goodman $\mathrm{R}$, eds. Congenital hemiplegia: clinics in developmental medicine. No. 150. London: MacKeith Press, 2000:98-112.

11. Õunpuu S, Deluca PA, Davis RB. Gait analysis. In: Neville B, Goodman R, eds. Congenital hemiplegia: clinics in developmental medicine. No. 150. London: MacKeith Press, 2000:81-97.

12. Rodda JM, Graham HK. Classification of gait patterns in spastic hemiplegia and spastic diplegia: a basis for a management algorithm. Eur J Neurol 2001;8/Suppl 5):98-108.

13. Perry J. The mechanics of walking in hemiplegia. Clin Orthop 1969;63:23-31.

14. Bobath K. The neurophysiological basis for the treatment of cerebral palsy: clinics in developmental medicine. No. 75. Spastics International Medical Publications, 1980.

15. Aminiam A, Vankoski SJ, Dias L, Novak RA. Spastic hemiplegic cerebral palsy and the femoral derotation osteotomy: effect at the pelvis and hip in the transverse plane during gait. J Pediatr Orthop 2003;23:314-20. 
16. Gage JR. Gait analysis in cerebral palsy. London: MacKeith Press, 1991.

17. Bax M. Terminology and classification of cerebral palsy. Dev Med Child Neurol 1964;6:295-307.

18. Keenan WN, Rodda J, Wolfe R, et al. The static examination of children and young adults with cerebral palsy in the gait analysis laboratory: technique and observer agreement. J Paediatr Orthop B 2004;13:1-8.

19. Boyd RN, Graham HK. Objective measurement of clinical findings in the use of botulinum toxin A for the management of children with cerebral palsy. Europ J Neuro 1999;6(Suppl 4):23-35

20. Medical Research Council. Aids to the investigation of peripheral nerve injuries war memorandum. No. 7. London: Her Majesty's Stationary Office, 1943.

21. Ruwe PA, Gage JR, Ozonoff MB, DeLuca PA. Clinical determination of femoral anteversion: a comparison with established techniques. J Bone Joint Surg [Am] 1992;74-A:820-30.

22. Staheli LT. Rotational problems of the lower extremities. Orthop Clin North Am 1987; $18: 503-12$

23. Staheli LT. The lower limb. In: Morrissy RT, ed. Lovell and Winter's pediatric orthopaedics, Third ed. Philadelphia: J.B. Lippincott Co, 1990:741-66.

24. Cusick BD, Stuberg WA. Assessment of lower-extremity alignment in the transverse plane: implications for management of children with neuromotor dysfunction. Phys Ther 1992;72:3-15.

25. Parrott J, Boyd RN, Dobson F, et al. Hip displacement in spastic cerebral palsy: repeatability of radiologic measurement. J Pediatr Orthop 2002;22:660-7.

26. Kadaba MP, Ramakrishnan HK, Wootten ME. Measurement of lower extremity kinematics during level walking. J Orthop Res 1990;8:383-92

27. Strayer LM. Recession of the gastrocnemius: an operation to relieve spastic contracture of the calf muscles. J Bone Joint Surg [Am] 1950;32-A:671-6.
28. White JW. Torsion of the Achilles tendon: its surgical difference. Arch Surg 1943;46: 784-7.

29. Graham HK, Fixsen JA. Lengthening of the calcaneal tendon in spastic hemiplegia by the White slide technique: a long-term review. J Bone Joint Surg [Br] 1988;70B:472-5.

30. Ruda R, Frost HM. Cerebral palsy: spastic varus and forefoot adductus, treated by intramuscular posterior tibial tendon lengthening. Clin Orthop 1971;79:61-70

31. Chambers H, Lauer A, Kaufman K, Cardelia JM, Sutherland D. Prediction of outcome after rectus femoris surgery in cerebral palsy: the role of cocontraction of the rectus femoris and vastus lateralis. J Pediatr Orthop 1998;18:703-11.

32. Sutherland DH, Zilberfarb JL, Kaufman KR, Wyatt MP, Chambers HG. Psoas release at the pelvic brim in ambulatory patients with cerebral palsy: operative technique and functional outcome. J Pediatr Orthop 1997;17:563-70.

33. Pirpiris M, Trivett A, Baker R, et al. Femoral derotation osteotomy in spastic diplegia: proximal or distal? J Bone Joint Surg [Br]2003;85-B:265-72.

34. Saraph V, Zwick EB, Zwick G, et al. Effect of derotation osteotomy of the femur on hip and pelvis rotations in hemiplegic and diplegic children. J Pediatr Orthop B 2002;11:159-66

35. Õunpuu S, Michalak RE, Romness M, Bell K, Deluca P. An evaluation of pelvic rotation pre- and post unilateral femoral derotation osteotomy in children with spastic hemiplegic cerebral palsy [abstract]. Dev Med Child Neurol 2002;44(Supp 91):5.

36. Wang R. Effect of proprioceptive neuromuscular facilitation on the gait of patients with hemiplegia of long and short duration. Phys Ther 1994;74:1108-15.

37. Bryce J. The management of spasticity in children. Physiotherapy 1976;62:353-7.

38. Wilkinson A, Pirpiris M, Nattrass GR, Graham HK. Walking speed in children with neuromuscular disease: a comparison between a 10-metre walk and a 10 minute walk [abstract]. Dev Med Child Neuro/ 2001;43(Supp 88):29-30. 